\title{
ERRATUM
}

\section{Estimation of groundwater recharge using water balance coupled with base-flow-record estimation and stable-base-flow analysis}

\author{
Cheng-Haw Lee $\cdot$ Wei-Ping Chen $\cdot$ Ru-Huang Lee
}

Published online: 25 November 2006

(C) Springer-Verlag 2006

\section{Erratum to: Environ Geol 51:73-82 DOI 10.1007/s00254-006-0305-2}

Unfortunately, the right column of page 76 contained two inadequate citations about references to Szilagyi et al. (2003). The manuscript is given correctly below.

Baseflow $\left(Q_{\mathrm{b}}\right)$ is obtained by employed the baseflow-record estimation and the stable-base-flow analysis. As a consequence, the drainage area value of the gauging station is used for the calculation of $N$, and Eq. 2 is employed through the introduction of the dimensionless base-flow index (BFI), which is the ratio of baseflow and total stream runoff $\left(Q=Q_{\mathrm{b}}+Q_{\mathrm{s}}\right)$ over time:

$\mathrm{BFI}=\frac{Q_{\mathrm{b}}}{Q_{\mathrm{b}}+Q_{\mathrm{s}}}$.

Inserting Eq. 4 into Eq. 2 yields the following equation from Szilagyi et al. (2003):

The online version of the original article can be found at http://dx.doi.org/10.1007/s00254-006-0305-2.

C.-H. Lee $(\bowtie)$ · W.-P. Chen

Department of Resources Engineering,

National Cheng Kung University, Tainan, Taiwan

e-mail: leech@mail.ncku.edu.tw

R.-H. Lee

Hydrology Division, Water Resources Agency,

Ministry of Economic Affairs, Taipei, Taiwan
$\mathrm{BFI} \times(P-E T)=\mathrm{BFI} \times q=q_{\mathrm{b}} \approx R$,

where $R\left(\mathrm{LT}^{-1}\right)$ is the yet unknown groundwater recharge, and $q=Q / A_{\mathrm{d}}$, with $A_{\mathrm{d}}$ denoting the contributing drainage area. Szilagyi et al. (2003) mentioned that the base-flow separation technique is only used to calculate BFI, but neither $q$ nor $q_{\mathrm{b}}$ were used in Eq. 5, because they require the extent of the contributing drainage area, $A_{\mathrm{d}}$, whereas BFI does not. When the two contributing areas for surface runoff and groundwater are known to be fairly close, then $q$ can be used in Eq. 5, eliminating the need for the $P$ and ET measurements.

\section{Reference}

Szilagyi J, Harvey FE, Ayers JF (2003) Regional estimation of base recharge to ground water using water balance and a base-flow index. Ground Water 41:504-513 